\title{
Prognosis of peripheral lung tumours related to size of the primary
}

\author{
TOM TREASURE AND J R BELCHER
}

\author{
From the London Chest Hospital, London
}

\begin{abstract}
Three hundred and fourteen cases of peripheral lung tumours managed surgically over a 15-year period have been analysed to re-examine the effect of tumour size on the probability of survival up to five years after operation. The cases were classified into four groups according to the size of the primary. There was a significant inverse relationship between tumour size and five-year survival over the four groups $(\mathrm{p}<0.05)$ but this relationship did not hold for the largest tumours. The tumours over $6 \mathrm{~cm}$ did no worse than the group one size smaller $(4 \cdot 5-6.0 \mathrm{~cm})$. Analysis of the survival in each group revealed a different pattern of annual loss in the largest tumours which suggested that this group included carcinomas self-selected for less metastatic potential. The peripheral tumours as a whole included more undifferentiated but fewer small cell carcinomas than the overall chest clinic figures. Within the peripheral tumours squamous carcinomas became more common and adenocarcinomas less common with increasing size. No small cell or adenocarcinomas were found among the five-year survivors in the large tumour group. Because $20 \%$ of patients with tumours over $6 \mathrm{~cm}$ lived for five years in this group of 314 patients we do not believe that they should be excluded from operative treatment on the basis of size alone.
\end{abstract}

The length of survival in lung cancer is inversely related to the size of the primary tumour and this relationship is similar in operated and non-operated groups. ${ }^{1}$ Surgical series report extremely poor results in large tumours. Wellons et $a l^{2}$ had no survivors when the primary tumour was greater than $5 \mathrm{~cm}$ in diameter. Yashar and $\mathrm{Yashar}^{3} \mathrm{re}^{\mathrm{r}}$ ported a similar size relationship and found no five-year survivors among those with large tumours (greater than $7.0 \mathrm{~cm}$ in their series). More recently Soorae and Abbey Smith ${ }^{4}$ found no 10-year survivors in a retrospective series of carcinomas greater than $7 \mathrm{~cm}$ in diameter; subsequently they studied 295 patients prospectively. The inverse relationship between size of the primary and survival was very clear and only $4.5 \%$ of patients with tumours greater than $7 \mathrm{~cm}$ were alive at two years. Freise $e t \mathbf{a l}^{5}$ found a similarly gloomy outlook but argued for operation on the large tumours on the grounds that it gave the only chance of "cure" and that resection of a large primary may prevent troublesome complications.

Address for reprint requests: $\mathrm{Mr}$ Tom Treasure, London Chest Hospital, Bonner Road, London E2 9JX.
The place of surgery in the management of lung cancer is being seriously questioned and the trend is towards more critical selection of patients and an overall reduction in the operation rate. The implication of the papers cited is that large size of the tumour is one of the factors which may sway the decision against operation. However, we continue to see patients in the follow-up clinic who have had very large tumours resected and yet remain well many years later. We therefore reviewed all the peripheral tumours operated on between 1960 and 1975 at two hospitals to establish the relationship between tumour size and survival in this group of patients.

Peripheral tumours are a convenient group to study because they can be reliably measured on the preoperative chest radiograph, ${ }^{1}$ and they include the larger primary tumours under discussion. ${ }^{4}$

\section{Patients and methods}

All patients admitted under the care of the senior author to one of two hospitals (Middlesex and 
London Chest Hospital) between 1960 and 1975 and who were identified on their record card as having peripheral tumours were included in the study. The completeness of this method of retrieval was verified in two ways. For two representative years the preoperative chest radiographs of all patients subjected to thoracotomy were reviewed and the correlation between patients identified in this way and by the cards was examined. Also, the pathology reports of all resected carcinomas for five consecutive years were studied. In both cases the card retrieval system was effectively complete. The card system has the advantage that the patients were identified prospectively, at the time of the original operation, so the composition of the study group could not have been biased by the result of surgery or by any subsequent events in their progress or management.

The last preoperative chest radiograph was reviewed in all patients. The tumour was measured without knowledge of the cell type or operative result. The diameter in centimetres was recorded. When the tumour was not round, two dimensions at right angles were taken and the average used. ${ }^{1}$ Measurements made in this way have been shown

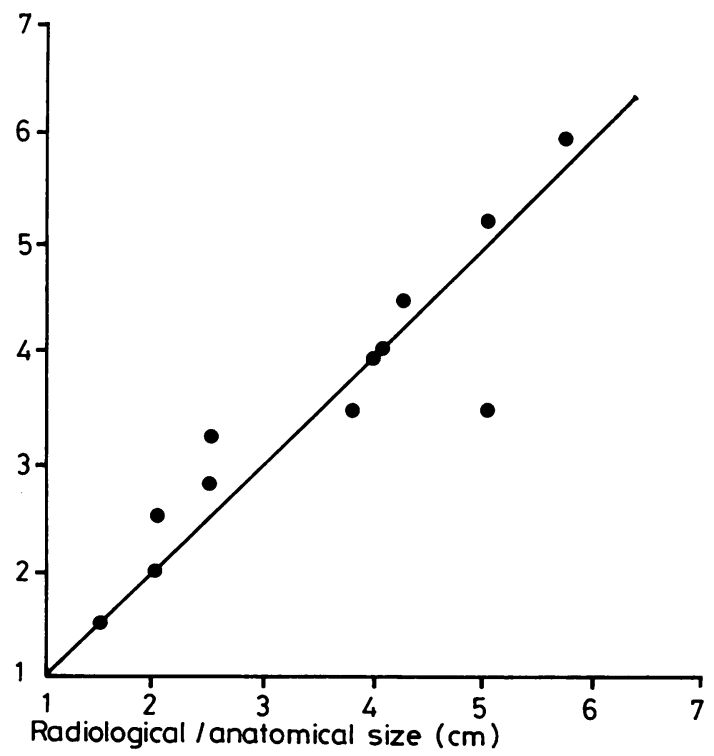

Fig 1 In 12 examples where the size of the pathological specimen was known the peripheral tumour was measured on the last preoperative radiograph and the two results compared. The radiological size is on the ordinate. The line of identity is given. The regression equation is: $y=0.53+0.86 x ; r=0.91 ; p<0.001$. to correlate well with the actual anatomical size of the tumour ${ }^{1}$ and we confirmed this early in the study (fig 1).

The patients were then classified into four groups (numbered 1 to 4 ) according to the size of the primary tumour $(0-3.0 \mathrm{~cm}, 3 \cdot 1-4.5 \mathrm{~cm}, 4 \cdot 6-6 \cdot 0$ $\mathrm{cm}$, and greater than $6 \mathrm{~cm}$ ) and the four groups compared for cell type, operative mortality rate, and survival up to five years.

\section{Results}

Three hundred and fourteen patients were identified as having a peripheral tumour and were included in the study. There was a preponderance of male patients by about $6: 1$. Lobectomy was the operation of choice and was possible in $72 \%$ of cases (table 1). Only $4 \%$ of patients had a thoracotomy without resection. The upper lobes were involved twice as often as the lower lobes and a review of the histology (fig 2) revealed a significantly increased incidence of undifferentiated carcinomas but fewer small cell tumours

Table 1 Operation performed in 314 patients with peripheral lung tumours

\begin{tabular}{lcc}
\hline Operation & Number of patients & Percentage \\
\hline Lobectomy & 218 & 70 \\
Pneumonectomy & 84 & 26 \\
Total resections & 302 & 96 \\
Thoracotomy alone & 12 & 4 \\
Totals & 314 & 100 \\
\hline
\end{tabular}

Table 2 Cell type in 314 peripheral lung tumours between 1960 and 1975 compared with the chest clinic cell types between 1966 and 1978

\begin{tabular}{lll}
\hline Cell type & $\begin{array}{l}\text { Surgical series } \\
(\%)\end{array}$ & $\begin{array}{l}\text { Chest clinic } \\
(\%)\end{array}$ \\
\hline Squamous & 53 & 49 \\
Undifferentiated & 20 & 12 \\
Adenocarcinoma & 18 & 15 \\
Small cell & 6 & 16 \\
Unknown & 3 & 8 \\
\hline
\end{tabular}

Table 3 Surgical result in 314 peripheral lung tumours grouped according to the size of the primary. The inverse relationship between size and five-year survival is significant $(p<0.05)$.

\begin{tabular}{lccll}
\hline Size $(\mathrm{cm})$ & Number & $\%$ resected & $\begin{array}{l}\text { Operative } \\
\text { mortality } \\
(\%)\end{array}$ & $\begin{array}{l}\text { Five-year } \\
\text { survival } \\
(\%)\end{array}$ \\
\hline $0-3.0 \mathrm{~cm}$ & 72 & 97 & 8 & 36 \\
$3.1-4.5 \mathrm{~cm}$ & 77 & 96 & 5 & 31 \\
$4.6-6.0 \mathrm{~cm}$ & 77 & 100 & 11 & 18 \\
over $6.0 \mathrm{~cm}$ & 88 & 92 & 17 & 20 \\
Totals & 314 & 96 & 11 & 26 \\
\hline
\end{tabular}




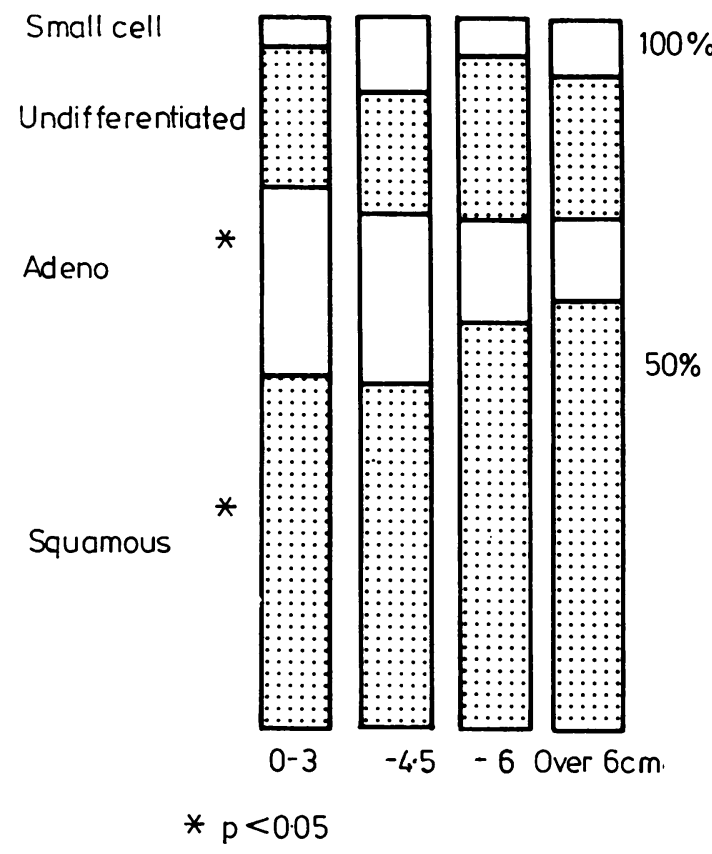

Fig 2 The distribution of histological types of tumours is given for the four size groups of peripheral tumours represented by the vertical bars. The increasing frequency of squamous carcinomas and the decreasing frequency of adenocarcinomas with increasing size of the tumours are significant $(p<0.05)$.

compared with the total chest clinic (LCH) figures for an overlapping 12-year period (table 2).

When ranked by tumour size, four conveniently even groups were obtained (table 3 ). The resection rate was lowest in the large tumour group (92\%) and the operative risk was higher (a 17\% mortality as opposed to $11 \%$ overall) but neither of these differences reached significance at the $5 \%$ level. The five-year survival was $26 \%$ for all resections. When analysed for each group (table 3) there is a highly significant inverse relationship between tumour size and five-year survival. This was the result of a better outlook in the smaller tumours; the two groups containing the larger tumours (3 and 4) had effectively the same survival at five years.

The percentage of patients surviving at yearly intervals is shown graphically for each of the four groups in fig 3 . The survival curves for the largest group and one size smaller cross between the second and third years. This is because, although the other groups continue to decline in numbers quite rapidly up to three years, the line for the

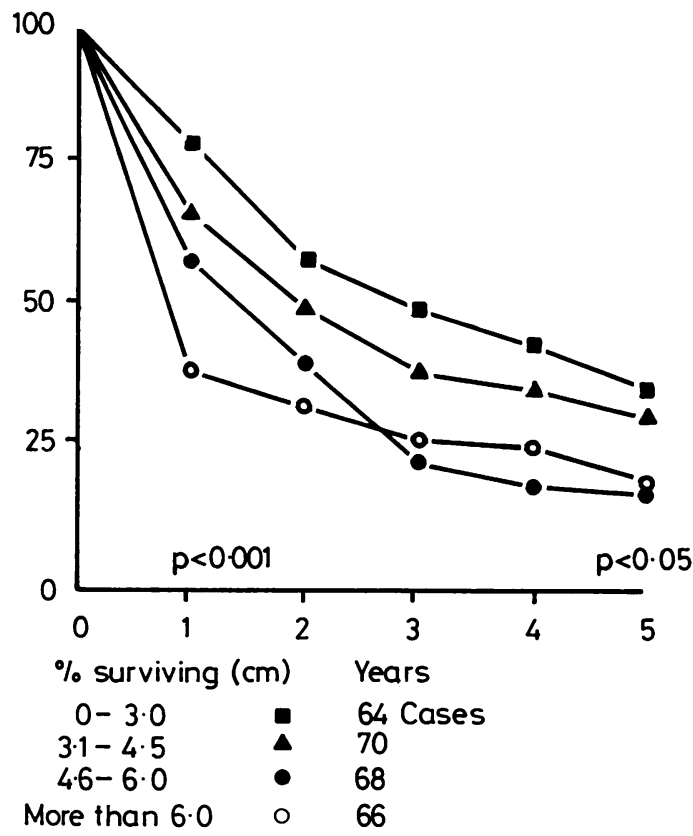

Fig 3 The numbers of patients surviving at yearly intervals after resection, in each of the four size groups of peripheral tumours, are plotted. The one-year survival has a highly significant inverse relationship with the size of the primary $(p<0.001)$. This is also present, but is less striking at five years $(p<0.05)$. This inverse relationship does not hold at five years in the larger tumour groups. If patients surviving at one year are followed to the second year, two-year survivors to the third year and so on, no size-related increase in mortality can be detected.

largest tumours has flattened out considerably after the first year. The percentage attrition between year one and year two is less in group 4 than any of the other groups. Comparing the two large tumour groups ( 3 and 4 ) by a fourfold table test between the first and second postoperative years this difference just fails to reach significance $(\mathrm{p}<0 \cdot 1)$ but in the opposite direction to that anticipated. After the third year comparison between the groups reveals no difference and the four lines run parallel.

All the small cell and adenocarcinomas in the largest group died before two years and nearly all the five-year survivors had squamous carcinomas.

\section{Discussion}

Our results confirm that patients with small tumours do better than those with large ones. They 
have a lower operative risk and a better five-year survival. However, before allowing this to influence our decision about operation, it is important to remember that these are also the patients who do well without operation and that the evidence which is available shows that survival rates are similar in operated and non-operated patients. ${ }^{18}$ Furthermore, our results do not show that large tumours inevitably do badly. Twenty per cent of cases are alive five years after operation and, even if we look only at the tumours greater than 7.0 $\mathrm{cm}$ to make our study more comparable with that of Soorae and Abbey Smith, the results are not significantly different.

The survival curves shown in fig 3 give us more information about the nature and behaviour of the large tumours than would simple five-year survival statistics. While the curves for groups 1-3 follow the pattern so often seen in survival plots, that of group 4 is a fundamentally different shape and looks as though it might be composed of two relatively discrete populations. We could speculate that group 4 includes examples of two types of tumours:

1 Those that are large because they are fastgrowing, aggressive tumours with relatively short doubling times. These are rapidly lethal whatever is done and they influence the first part of the survival plot, before one year.

2 Those that become large because they are less likely to metastasise and whose existence is compatible with continuing survival of the patient. After resection they might be expected to do well because any residual tumour, local or distant, will also be slow-growing. These dominate the later part of the survival plot.

These results re-emphasise the fallacy of regarding tumour growth as following a particular time course and therefore of regarding a radiographic measurement as telling us the point a particular tumour has reached in its life history. The large variation in growth rates $^{7} 8$ which has been observed in serial radiographs makes this sort of interpretation of a single radiograph of limited value in assessing the outlook for a given tumour.
However, the first radiograph which shows the tumour has usually been the one which demands action and this may be the only information on which a decision is made.

We conclude from our review of these 314 patients that, while small tumours have a better five-year survival than large ones, a number of patients with large tumours $(20 \%)$ survive five years after operation. Among the tumours which are large at the time of presentation there are those which appear to be self-selected for little metastatic potential and the outlook is sufficiently good to justify removal of the lung primary. Because we cannot identify with any accuracy those that will do well, it seems reasonable to continue to offer resection for large tumours that are otherwise suitable for operation. We also note that once a patient has survived three years after resection the chance of continued survival is then independent of the size of the original tumour.

\section{References}

1 Weiss W, Boucot KR. The prognosis of lung cancer originating as a round lesion. Am Rev Respir Dis 1977; 116:827-36.

2 Wellons HA, Johnson G, Benson WR, Pate D, Wilcox BR, Peters RM. Prognostic factors in malignant tumors of the lung. Ann Thorac Surg 1968; 5:228-35.

3 Yashar J, Yashar JJ. Factors affecting long-term survival of patients with bronchogenic carcinoma. Am J Surg 1975; 129:386-93.

4 Soorae AS, Abbey Smith R. Tumour size as a prognostic factor after resection of lung carcinoma. Thorax 1977; 32:19-25.

5 Freise G, Gabler A, Liebig S. Bronchial carcinoma and long-term survival. Thorax 1978; 33:228-34.

6 Geddes DM. The natural history of lung cancer; a review based on rates of tumour growth. $\mathrm{Br} J$ Dis Chest 1979; 73:1-17.

7 Weiss W: Peripheral measurable bronchogenic carcinoma: growth rate and period of risk after therapy. Am Rev Respir Dis 1971; 103:198-208.

8 Steele JD, Buell P. Asymptomatic solitary pulmonary nodules. J Thorac Cardiovasc Surg 1973; 65: $140-51$. 